\section{Glenohumeral joint capsular tissue tension loading correlates moderately with shear wave elastography: a cadaveric investigation}

\author{
Charles W. Nichols', Jean-Michel Brismée ${ }^{2}$, Troy L. Hooper², \\ Antony Bertrand-Grenier ${ }^{3,4,5}$, Kerry K. Gilbert ${ }^{2}$, Marc-Olivier St-Pierre ${ }^{6}$, Jeegisha Kapila ${ }^{7}$, \\ Stéphane Sobczak ${ }^{6,8}$
}

*Author affiliations appear at the end of this article.

Purpose: The purpose of this study was to investigate changes in the mechanical properties of capsular tissue using shear wave elastography (SWE) and a durometer under various tensile loads, and to explore the reliability and correlation of SWE and durometer measurements to evaluate whether SWE technology could be used to assess tissue changes during capsule tensile loading.

Methods: The inferior glenohumeral joint capsule was harvested from 10 fresh human cadaveric specimens. Tensile loading was applied to the capsular tissue using 1-, 3-, 5-, and 8-kg weights. Blinded investigators measured tissue stiffness and hardness during loading using SWE and a durometer, respectively. Intraobserver reliability was established for SWE and durometer measurements using intraclass correlation coefficients (ICCS). The Pearson product-moment correlation was used to assess the associations between SWE and durometer measurements.

Results: The ICC 3,5 for durometer measurements was 0.90 (95\% confidence interval [CI], 0.79 to $0.96 ; \mathrm{P}<0.001)$ and $0.95(95 \% \mathrm{Cl}, 0.88$ to $0.98 ; \mathrm{P}<0.001)$ for SWE measurements. The Pearson correlation coefficient values for $1-, 3-$, and $5-k g$ weights were $0.56(P=0.095), 0.36(P=0.313)$, and $-0.56(P=0.089)$, respectively. When the 1 - and $3-\mathrm{kg}$ weights were combined, the $\mathrm{ICC}_{3,5}$ was $0.72(P<0.001)$, and it was $0.62(P<0.001)$ when the $1-, 3-$, and $5-\mathrm{kg}$ weights were combined. The 8-kg measurements were severely limited due to SWE measurement saturation of the tissue samples.

Conclusion: This study suggests that SWE is reliable for measuring capsular tissue stiffness changes in vitro at lower loads ( 1 and $3 \mathrm{~kg}$ ) and provides a baseline for the non-invasive evaluation of effects of joint loading and mobilization on capsular tissues in vivo.

Keywords: Joint capsule; Elasticity; Hardness; Elastography; Reliability

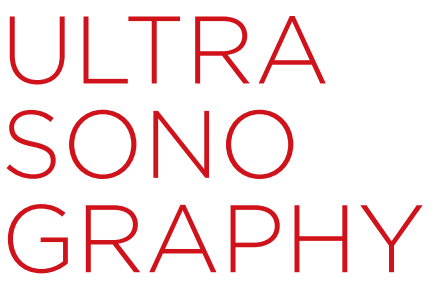

ORIGINAL ARTICLE

https://doi.org/10.14366/usg.19032 pISSN: 2288-5919 e elSSN: 2288-5943 Ultrasonography 2020;39:114-120

Received: June 5, 2019

Revised: July 31, 2019

Accepted: August 1, 2019

Correspondence to:

Charles W. Nichols, PT, DPT, MEd, ScD, Department of Physical Therapy, School of Health Professions, University of North Texas Health Science Center, 3500 Camp Bowie, MET 533, Ft. Worth, TX, USA

Tel. +1-817-735-2681

Fax. +1-817-735-2518

E-mail: charles.nichols@unthsc.edu

This is an Open Access article distributed under the terms of the Creative Commons Attribution NonCommercial License (http://creativecommons.org/ licenses/by-nc/4.0/) which permits unrestricted noncommercial use, distribution, and reproduction in any medium, provided the original work is properly cited.

Copyright (C) 2020 Korean Society of Ultrasound in Medicine (KSUM)

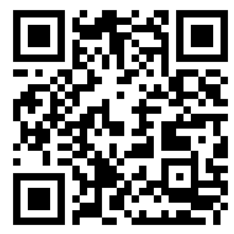

How to cite this article:

Nichols CW, Brismée JM, Hooper TL, Grenier AB, Gilbert KK, St-Pierre MO, et al. Glenohumeral joint capsular tissue tension loading correlates moderately with shear wave elastography: a cadaveric investigation. Ultrasonography. 2020 Apr;39(2):114-120. 


\section{Introduction}

The glenohumeral joint (GHJ) is a frequent site of pain and pathology with a reported prevalence from $7 \%$ to $23 \%$ in adults $[1,2]$. GHJ osteoarthritis can affect up to $33 \%$ of people over 60 years of age $[3,4]$ and adhesive capsulitis affects $2 \%-5 \%$ of the general population and $10 \%-15 \%$ of individuals with diabetes $[5,6]$. In adhesive capsulitis, the capsule becomes contracted and thicker, particularly in the infraglenoid recess and rotator cuff interval [79], which limits joint mobility [10]. Inferior capsule thickening of more than $3.5 \mathrm{~mm}$ recorded using ultrasound is $66.7 \%$ sensitive and $92.5 \%$ specific for the diagnosis of shoulder adhesive capsulitis [11]. Capsular tissue elasticity affects range of motion (ROM), or the allowed amount of joint plane-specific motion (e.g., GHJ flexion), more than thickness, indicating a need for capsular tissue stiffness measurements [12]. Capsular tightness restricts joint ROM and increases joint contact pressures, leading to intra-articular pathology [13] and limiting the ability to complete basic activities, such as dressing and hygiene [3]. Clinicians commonly manage patients with ROM limitations, functional impairments, and pain using stretching and joint mobilization techniques [14-16]. Several authors [17-19] reported that GHJ mobilization using loads of 20-80 N increased capsule extensibility or elongation and improved patient symptoms $[20,21]$. The proposed mechanical and neurophysiological changes responsible for increased joint ROM following joint mobilizations are not well understood and require further investigation [22]. Shear wave elastography (SWE) measurements are a reproducible method of evaluating muscle and tendon [23-26], with good repeatability, as demonstrated by intraclass coefficients (ICCS) of $0.81-0.91$. This allows SWE to provide information on tissue diagnosis, injury, and/ or healing states $[27,28]$. However, no study has validated SWE readings in capsular tissue against a reference standard. Therefore, the purpose of this study was to investigate: (1) the reliability of SWE measurements of GHJ capsular tissue under various loads; and (2) the degree of correlation between measurements of GHJ capsular tissue tension properties under various loads made using a durometer versus SWE.

\section{Materials and Methods}

This study was approved by the Ethics Sub-committee of the Department of Anatomy at the Université du Québec à Trois-Rivières, Trois-Rivières, Québec and exempted by the University of North Texas Regional Institutional Review Board. A convenience sample of 10 frozen GHJ specimens (5 right and 5 left) was acquired from five fresh cadavers through the Department of Anatomy at the Université du Québec à Trois-Rivières. The specimens included four males and one female, with a mean age of $77.8 \pm 5.4$ years, height of $1.65 \pm 0.09$ $\mathrm{m}$, weight of $59.6 \pm 15.67 \mathrm{~kg}$, and body mass index of $21.6 \pm 5.31$ $\mathrm{kg} / \mathrm{m}^{2}$.

The inferior capsular attachment to the humerus and scapula was excised along with the GHJ capsule to allow for testing. The samples were then trimmed to a 12-mm width for testing. The specimens were then placed in containers and frozen in storage until needed at $-20^{\circ} \mathrm{C}$. Tissue specimens were thawed for $1-2$ hours and then tested at room temperature $\left(18^{\circ} \mathrm{C}\right)$. Tissue specimens were connected to a standing frame using a custom clamp and a rope with the attached load (Fig. 1) along with a random selection of 1-, 3-, 5-, and 8-kg loads for measurements using SWE and the durometer. Investigators recording the durometer and SWE measurements were blinded to the loads applied to the tissue samples.

\section{SWE Measurements}

The SWE procedures were performed at a regional health and social services center (Centre Intégré Universitaire de Santé et de Services Sociaux de la Mauricie-et-du-Centre-du-Québec). An Aixplorer (SuperSonic Imagine, Aix-en-Provence, France) diagnostic device was used, with an XL-15-4 linear transducer that allowed the investigator to quantify tissue elasticity without probe compression.

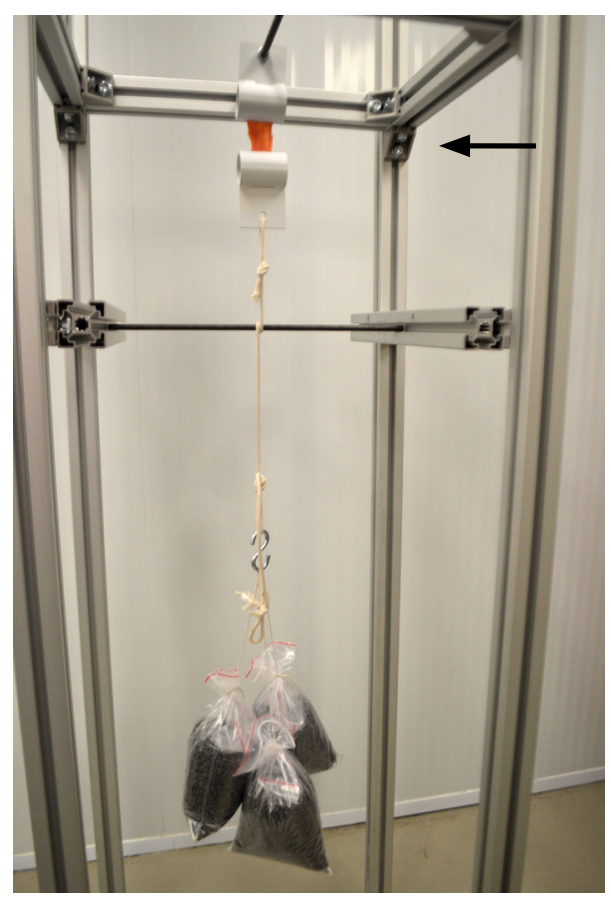

Fig. 1. Testing frame set-up. A standing frame with custom clamps secured superiorly and inferiorly with a suspended $3-\mathrm{kg}$ weight and stabilizing bar. The arrow indicates the location of the glenohumeral joint capsular tissue prior to application of the gelatin pad. 
The investigator performing the SWE measurements was a medical physicist with over 8 years of experience using SWE and 10 years of image processing.

Ultrasound gel was placed on the sample tissue followed by application of a conforming gelatin pad, and the specimen was secured with Opsite Flexifix (Smith \& Nephew, Andover, MA, USA) (Fig. 2). The ultrasound gel was applied to the Opsite covering and then visualized with B-mode ultrasound. Once an acceptable image of the capsular tissue was achieved, the SWE was activated and the image scanned for best resolution. Once the region of interest (ROI) was identified in the Q-box, which provides the field of view, the probe was removed. The ROI was then marked and saved using

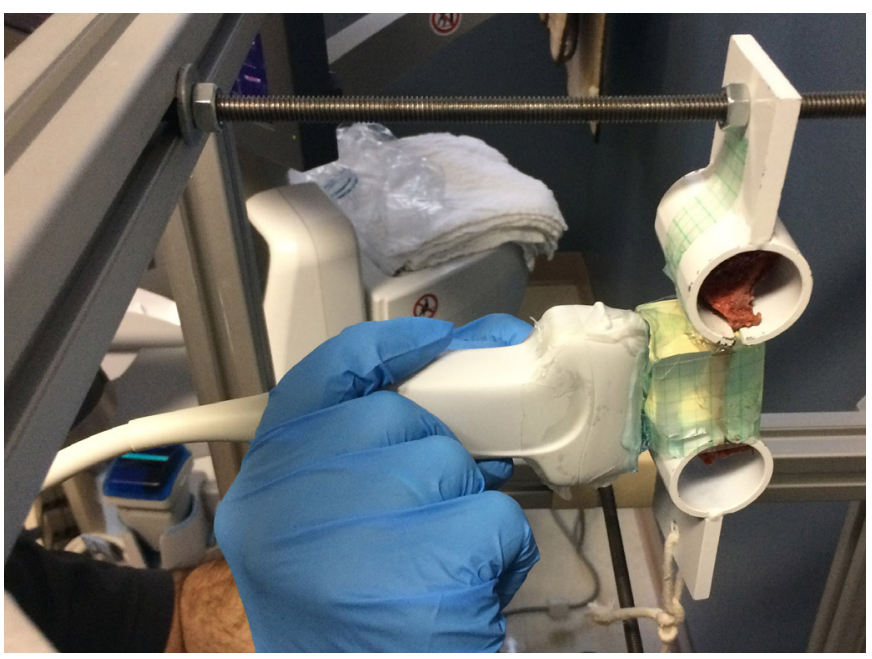

Fig. 2. Measurement set-up for tissue. The shear wave elastography measurements of capsular tissue were made using a linear transducer over tissue surrounded by gelatin and secured by Opsite Flexifix material.

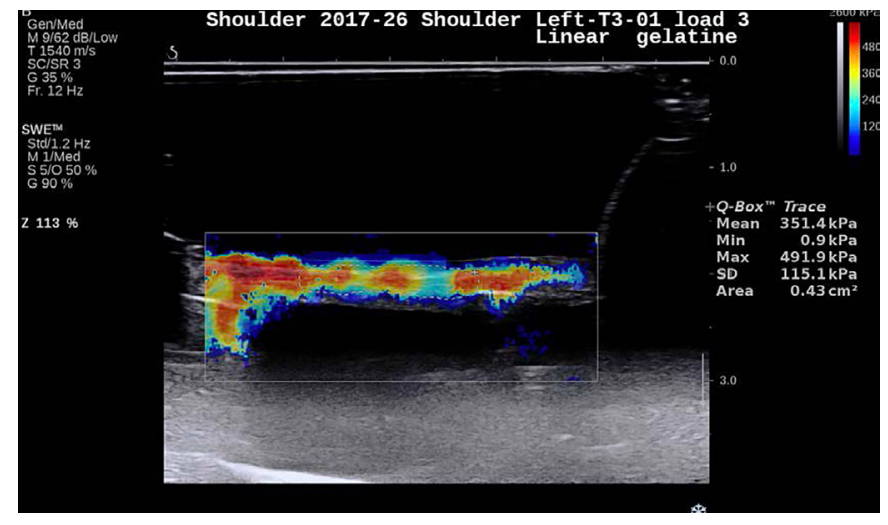

A

Fig. 3. Shear wave elastography Q-box measurements.

A. The display demonstrates statistical information and a non-saturated display within the region of interest, which is identified within the dotted line. B. The display demonstrates statistical information and a saturated display within the region of interest, which is identified within the dotted line. the Q-box tracer and used to acquire a measurement of elasticity $(\mathrm{kPa})$ within the Q-box data area. Data were obtained for five measurements from each tissue specimen using loads of $1,3,5$, and $8 \mathrm{~kg}$ for the shoulder in three trials to assess reliability (Fig. 3). The reliability and correlation analyses were calculated using the mean measurements obtained for each load of each trial.

\section{Durometer}

The Shore A durometer (HT-6510A Shore A, Tongbao, Shenzhen, (hina), a digital, hand-held, spring-loaded device (Fig. 4), was calibrated, and the pressor was applied parallel to midportion of tissue specimens and held in contact for 1-2 seconds until a measurement was obtained. This was repeated for five measurements using randomly selected 1-, 3-, 5-, and 8-kg loads in two trials separated by at least 5 -minute intervals by a blinded investigator to assess reliability. Data were recorded for five measurements from the tissue specimens at each load in three trials to assess reliability (Fig. 4).

Descriptive statistics including mean, median, standard deviation, ranges, and minimum/maximum values were calculated for the durometer and SWE measurements. The reliability of the durometer and SWE measurements was established using the intraclass correlation coefficient $\left(\mathrm{ICC}_{3,5}\right)$. Data normality was assessed using the Shapiro-Wilk test, which indicated that the SWE and durometer measurements were normally distributed for the 1-, 3-, and $5-\mathrm{kg}$ loads (SWE, $\mathrm{P}=0.572-0.960$; durometer, $\mathrm{P}=0.441-0.730$ ), and the kurtosis and skewness coefficients were lower than \pm 1 . Therefore, the associations between SWE and durometer measurements were assessed with Pearson correlation coefficients. Statistical significance was set at $\mathrm{P}<0.05$ for all analyses. All data and statistical analyses

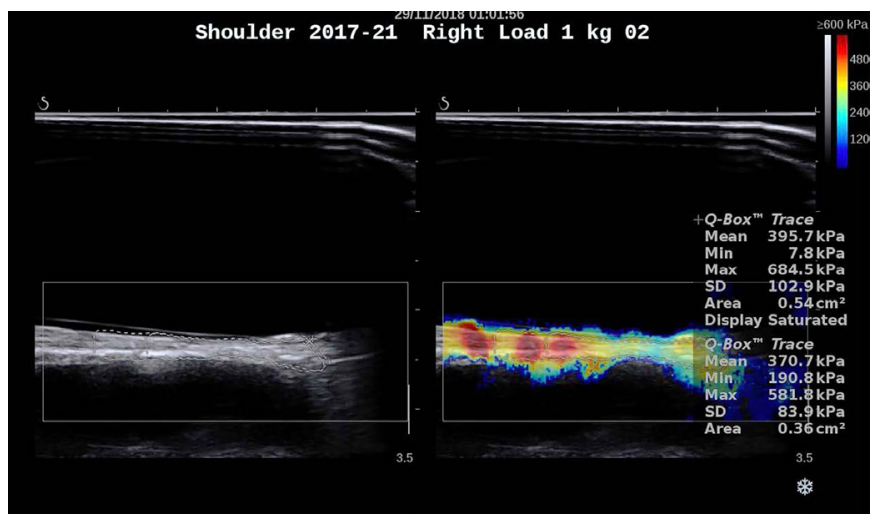

B 


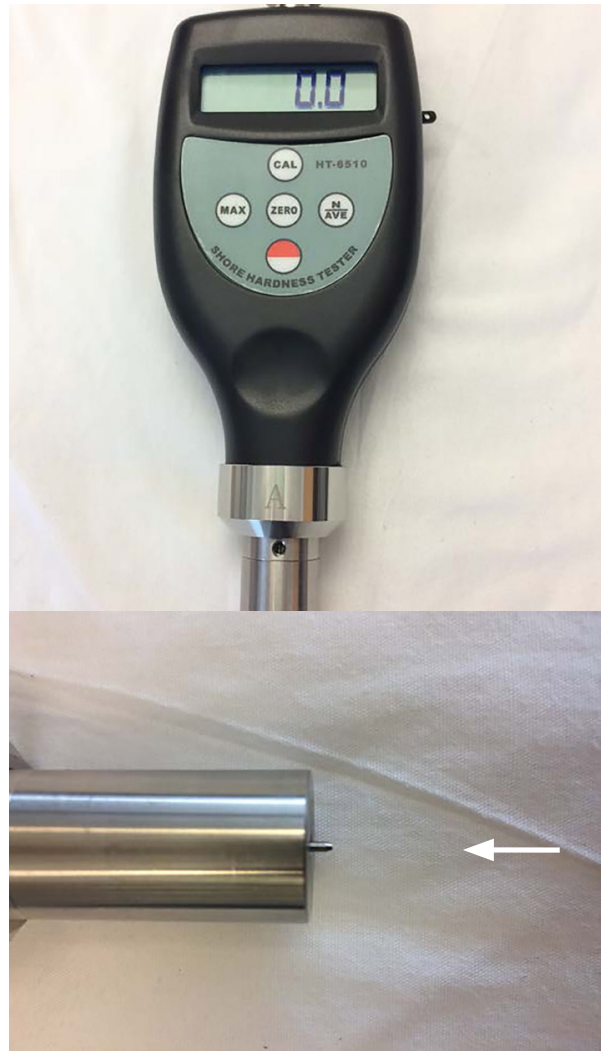

Fig. 4. Shore A durometer. The arrow indicates the device indenter.

were performed using IBM SPSS statistics version 23 software (IBM Corp., Armonk, NY, USA).

\section{Results}

The SWE and durometer measurement values are shown in Table 1.

The intra-day reliability of the durometer measurements was 0.90 (95\% confidence interval $[\mathrm{Cl}], 0.79$ to $0.96 ; \mathrm{P}<0.001)$ and that of the SWE measurements was $0.95(95 \% \mathrm{Cl}, 0.88$ to 0.98 ; $\mathrm{P}<0.001)$. A moderate correlation was observed between the durometer and SWE tissue tensile loading measurements at 1 $\mathrm{kg}(\mathrm{r}=0.56, \mathrm{P}=0.095), 1$ and $3 \mathrm{~kg}$ combined $(r=0.72, P<0.001)$, and 1,3 , and $5 \mathrm{~kg}$ combined $(r=0.62, P<0.001)$, with a slight correlation at $3 \mathrm{~kg}(\mathrm{r}=0.36, \mathrm{P}=0.313)$. The $5-\mathrm{kg}$ load demonstrated a moderate negative correlation $(r=-0.56, P=0.089)$, which can likely be explained at least partially by the $800-\mathrm{kPa}$ maximum SWE limit causing a ceiling effect. The 8-kg load could not be measured consistently due to tissue thinness with loading and SWE sample saturation with the 800-kPa measurement limit.
Table 1. Mean durometer and SWE measurements under loads of 1,3 , and $5 \mathrm{~kg}$

\begin{tabular}{ccc}
\hline Load $(\mathrm{kg})$ & Durometer (HA) & SWE $(\mathrm{kPa})$ \\
\hline 1 & $9.4 \pm 1.8$ & $277.1 \pm 30.0$ \\
3 & $15.6 \pm 2.5$ & $354.2 \pm 33.0$ \\
5 & $18.7 \pm 2.5$ & $410.2 \pm 37.2$ \\
\hline
\end{tabular}

Values are presented as mean \pm SD.

SWE, shear wave elastography; HA, hardness unit of Shore A durometer; SD, standard deviation.

\section{Discussion}

This is the first study to assess the reliability of SWE and correlations between the durometer and SWE for GHJ capsular tissue properties under clinically applicable tensile loads using cadaveric tissue to eliminate neuromuscular influences. Tensile loads were selected based on pilot testing of the durometer for capsular tissue with good reliability (ICC $3,5,0.87 ; 95 \% \mathrm{Cl}, 0.68$ to 0.95$)$ and a high correlation between the tensile load applied and durometer measurements for loads of 1,2 , and $5 \mathrm{~kg}$, as well as other prior studies of $\mathrm{GHJ}$ tissue properties $[17,18,29]$. The SWE measurements for reliability and correlation in this study were performed by one observer in 1 day. The mean of five successive measurements was used to determine reliability. This design provided the best conditions to determine SWE reliability values. In this SWE study, the machine's Q-box provided measurement selection through identification of the shear ROI. However, when the 5- and 8-kg loads were applied, saturation in some specimens due to the 800-kPa maximum SWE limit affected the mean tissue shear measurements, thereby creating a ceiling effect, which could have affected measurement validity at higher loads. Our findings showed that GHJ capsular tissue measurements under tensile loading using SWE had excellent reliability (ICC, 0.95). These findings suggest that SWE is reliable for measuring GHJ capsular tissue in cadavers during tensile loading. These results are in line with a previous in vivo study that evaluated GHJ capsular thickness and elasticity in two different positions, with an intra-rater reliability value of 0.93 for posterior-inferior capsule elasticity [12].

Previous studies reported ROM changes after mobilization $[5,18]$ and tissue elongation after simulated oscillations [29], but a better understanding of how these interventions affect tissue properties is needed. This study demonstrated that SWE technology may allow non-invasive measurement of tissue changes during joint loading and capsule stretching procedures. Future studies evaluating the effects of tensile loading on capsular tissue in vivo are warranted to determine capsule behaviors during various mobilizations and whether changes in tissue properties are maintained post-loading. 
A durometer measures a material's hardness or resistance to deformation by applying an indentation load on the specimen, giving a measure of tissue hardness based on an arbitrary Shore unit (HA) $[30,31]$. Durometers have been used in various medical applications, such as in dermatology $[32,33]$ and for measurements of organ [34-36], breast [37], and muscle [38] tissue. The intrarater and inter-rater reliability measures of durometer measurements of epidermal tissue were good to excellent [32,33]. However, reliability has not been established in capsular tissue. Likewise, GHJ capsule hardness measurements with a durometer had high intra-rater reliability (ICC, 0.90) and could be used as a control method to validate diagnostic methods such as SWE [34]. These findings establish the durometer as a reliable and simple tool for measuring capsular tissue hardness in vitro. Selected durometer measurements at higher loads were difficult to obtain due to tissue sample thinness, which affected the consistency of the measurement location in some specimens. This may explain why the reliability coefficients were not as high as those reported by Kissin et al. [33]; however, our results were at the higher part of the range reported by Merkel et al. [32] for epithelial tissue measurements.

A modest correlation was observed between SWE and durometer measurements of GHJ capsular tissue stiffness and hardness for the 1-kg load and the 1- and $3-\mathrm{kg}$ loads combined, and a small correlation was found with the $3-\mathrm{kg}$ tensile loads. This indicates that as the load increased, GHJ capsule stiffness as measured by SWE and hardness as measured by the durometer increased at lower loads. Similar correlation values between B-mode ultrasonography and durometer measurements were reported in muscle tissue [38], indicating that both modalities measure different parameters that are closely related to the modulus of elasticity. Achilles tendon tensile loads and SWE have been moderately correlated under progressive loads [39]. In the current study, the $5-\mathrm{kg}$ tensile load resulted in a moderate negative correlation between the durometer and SWE measurements; these results should be viewed with caution due to tissue thinness, inconsistencies in the location of the durometer and SWE measurement locations, and SWE saturation levels at the $5-\mathrm{kg}$ tensile load.

There are some advantages of using SWE to evaluate joint capsule properties. First, it is a reliable measurement modality and can conveniently and quickly assess the elastic properties of a joint capsule. In the present study, the time required for scanning and evaluating the capsule was only a few minutes. These advantages make SWE a promising modality to diagnose capsular pathology and to evaluate treatment progression and the efficacy of different interventions.

There were some limitations to our study. Soft tissues around the capsule were removed by hand and although great care was taken to clear other tissue from around the capsule, any remaining noncapsular tissue could have contributed to some load resistance. Studies evaluating whether such properties are maintained over time and using other joint capsular tissue would be valuable. Further research is needed to determine the effects of tensile loading on capsular tissue and to provide insight into the effects of stretching and joint mobilization loads on joint ROM changes in vivo.

In conclusion, SWE is a simple and reliable method of measuring the elastic properties of the GHJ capsule in cadaveric tissue. Additional research is required for the evaluation of capsular tissue tension properties during and following various loads, without the interference of the neuromuscular system, using SWE.

ORCID: Charles W. Nichols: https://orcid.org/0000-0001-6379-2445; Jean-Michel Brismée: https://orcid.org/0000-0002-1037-7704; Troy L. Hooper: https://orcid.org/00000003-3436-2993; Antony Bertrand-Grenier: https://orcid.org/0000-0001-5965-9254; Kerry K. Gilbert: https://orcid.org/0000-0003-4899-4617; Marc-Olivier St-Pierre: https://orcid.org/0000-0003-1638-2915; Jeegisha Kapila: https://orcid.org/00000003-1430-1149; Stéphane Sobczak: https://orcid.org/0000-0002-9223-7982

\section{Author Contributions}

Conceptualization: Nichols CW, Brismée JM, Hooper TL, Kapila J, Gilbert KK. Data acquisition: Nichols CW, Brismée JM, BertrandGrenier A, St-Pierre MO, Sobczak S. Data analysis or interpretation: Nichols CW, Brismée JM, Sobczak S. Drafting of the manuscript: Nichols CW, Brismée JM, Sobczak S. Critical revision of the manuscript: Brismée JM, Hooper TL, Kapila J, Bertrand-Grenier A, Gilbert KK, Sobczak S. Approval of the final version of the manuscript: all authors.

\section{${ }^{*}$ Author affiliations}

'Department of Physical Therapy, School of Health Professions, University of North Texas Health Science Center, Ft. Worth, TX; ${ }^{2}$ Department of Rehabilitation Sciences, Center for Rehabilitation Research, Texas Tech University Health Sciences Center, Lubbock, TX, USA; ${ }^{3}$ Centre Intégré Universitaire de Santé et de Services Sociaux de la Mauricie-et-du-Centre-du-Québec (CIUSSS MCQ), TroisRivières, Québec; ${ }^{4}$ Centre Hospitalier Affilié Universitaire Régional, Centre Intégré Universitaire de Santé et de Services Sociaux de la Mauricie-et-du-Centre-du-Québec (CIUSSS MCQ), Trois-Rivières, Québec; ${ }^{5}$ Département de Chimie, Biochimie et Physique, Université du Québec à Trois-Rivières, Trois-Rivières, Québec; ${ }^{6}$ Département d'Anatomie, Université du Québec à Trois-Rivières, Trois-Rivières, Québec, Canada; ${ }^{7} T e x a s$ Tech University Health Sciences Center, Lubbock, TX, USA; ${ }^{8}$ Unite de Recherche en Anatomie Clinique et Fonctionnelle (URACEF), Trois-Rivires, Québec, Canada 


\section{Conflict of Interest}

No potential conflict of interest relevant to this article was reported.

\section{Acknowledgments}

We would like to express our deepest gratitude to the people and their families who donate their bodies for educational and research purposes. Without their contribution, studies like this one would not be possible. We would like to acknowledge Dany Lemay and Jonathan St-Arnaud from the department of mechanical engineering for their help in the experimental set-up.

\section{References}

1. Wofford JL, Mansfield RJ, Watkins RS. Patient characteristics and clinical management of patients with shoulder pain in U.S. primary care settings: secondary data analysis of the National Ambulatory Medical Care Survey. BMC Musculoskelet Disord 2005;6:4.

2. Luime JJ, Koes BW, Hendriksen IJ, Burdorf A, Verhagen AP, Miedema $H S$, et al. Prevalence and incidence of shoulder pain in the general population; a systematic review. Scand J Rheumatol 2004;33:7381.

3. Menge TJ, Boykin RE, Byram IR, Bushnell BD. A comprehensive approach to glenohumeral arthritis. South Med J 2014;107:567573.

4. Chillemi C, Franceschini V. Shoulder osteoarthritis. Arthritis 2013;2013:370231.

5. Paul A, Rajkumar JS, Peter S, Lambert L. Effectiveness of sustained stretching of the inferior capsule in the management of a frozen shoulder. Clin Orthop Relat Res 2014;472:2262-2268.

6. Aydeniz A, Gursoy S, Guney E. Which musculoskeletal complications are most frequently seen in type 2 diabetes mellitus? I Int Med Res 2008:36:505-511.

7. Suh $C H$, Yun SJ, Jin W, Lee SH, Park SY, Park JS, et al. Systematic review and meta-analysis of magnetic resonance imaging features for diagnosis of adhesive capsulitis of the shoulder. Eur Radiol 2019;29:566-577.

8. Lewis J. Frozen shoulder contracture syndrome: aetiology, diagnosis and management. Man Ther 2015;20:2-9.

9. Sridharan R, Engle MP, Garg N, Wei W, Amini B. Focal uptake at the rotator interval or inferior capsule of shoulder on (18)F-FDG PET/CT is associated with adhesive capsulitis. Skeletal Radiol 2017;46:533538.

10. Lee SY, Lee KJ, Kim W, Chung SG. Relationships between capsular stiffness and clinical features in adhesive capsulitis of the shoulder. PM R 2015;7:1226-1234.

11. Cheng X, Zhang Z, Xuanyan G, Li T, Li J, Yin L, et al. Adhesive capsulitis of the shoulder: evaluation with US-arthrography using a sonographic contrast agent. Sci Rep 2017;7:5551.
12. Takenaga T, Sugimoto K, Goto H, Nozaki M, Fukuyoshi M, Tsuchiya A, et al. Posterior shoulder capsules are thicker and stiffer in the throwing shoulders of healthy college baseball players: a quantitative assessment using shear-wave ultrasound elastography. Am J Sports Med 2015;43:2935-2942.

13. Richards DP, Burkhart SS. Arthroscopic debridement and capsular release for glenohumeral osteoarthritis. Arthroscopy 2007;23:10191022.

14. Kelley MJ, Shaffer MA, Kuhn JE, Michener LA, Seitz AL, Uhl TL, et al. Shoulder pain and mobility deficits: adhesive capsulitis. J Orthop Sports Phys Ther 2013;43:A1-A31.

15. Lin HT, Hsu AT, An KN, Chang Chien JR, Kuan TS, Chang GL. Reliability of stiffness measured in glenohumeral joint and its application to assess the effect of end-range mobilization in subjects with adhesive capsulitis. Man Ther 2008;13:307-316.

16. Bang MD, Deyle GD. Comparison of supervised exercise with and without manual physical therapy for patients with shoulder impingement syndrome. J Orthop Sports Phys Ther 2000;30:126137.

17. Hsu AT, Ho L, Chang JH, Chang GL, Hedman T. Characterization of tissue resistance during a dorsally directed translational mobilization of the glenohumeral joint. Arch Phys Med Rehabil 2002;83:360-366.

18. Hsu AT, Ho L, Ho S, Hedman T. Immediate response of glenohumeral abduction range of motion to a caudally directed translational mobilization: a fresh cadaver simulation. Arch Phys Med Rehabil 2000:81:1511-1516.

19. Cereatti A, Calderone M, Buckland DM, Buettner A, Della Croce U, Rosso C. In vivo glenohumeral translation under anterior loading in an open-MRI set-up. J Biomech 2014;47:3771-3775.

20. Johnson AJ, Godges JJ, Zimmerman GJ, Ounanian LL. The effect of anterior versus posterior glide joint mobilization on external rotation range of motion in patients with shoulder adhesive capsulitis. J Orthop Sports Phys Ther 2007;37:88-99.

21. Tyler TF, Nicholas SJ, Lee SJ, Mullaney M, McHugh MP. Correction of posterior shoulder tightness is associated with symptom resolution in patients with internal impingement. Am J Sports Med 2010;38:114-119.

22. Talbott NR, Witt DW. In vivo measurements of humeral movement during posterior glenohumeral mobilizations. J Man Manip Ther 2016;24:269-276.

23. Payne C, Watt $P$, Cercignani M, Webborn N. Reproducibility of shear wave elastography measuresof the Achilles tendon. Skeletal Radiol 2018:47:779-784.

24. Peltz CD, Haladik JA, Divine G, Siegal D, van Holsbeeck M, Bey MJ. ShearWave elastography: repeatability for measurement of tendon stiffness. Skeletal Radiol 2013;42:1151-1156.

25. Rosskopf AB, Ehrmann C, Buck FM, Gerber C, Fluck M, Pfirrmann CW. Quantitative shear-wave US elastography of the supraspinatus 
muscle: reliability of the method and relation to tendon integrity and muscle quality. Radiology 2016;278:465-474.

26. Tas S, Onur MR, Yilmaz S, Soylu AR, Korkusuz F. Shear wave elastography is a reliable and repeatable method for measuring the elastic modulus of the rectus femoris muscle and patellar tendon. J Ultrasound Med 2017;36:565-570.

27. Youk JH, Son EJ, Park AY, Kim JA. Shear-wave elastography for breast masses: local shear wave speed $(\mathrm{m} / \mathrm{sec})$ versus Young modulus (kPa). Ultrasonography 2014;33:34-39.

28. Ryu J, Jeong WK. Current status of musculoskeletal application of shear wave elastography. Ultrasonography 2017;36:185-197.

29. Muraki T, Yamamoto N, Berglund LJ, Sperling JW, Steinmann SP, Cofield RH, et al. The effect of cyclic loading simulating oscillatory joint mobilization on the posterior capsule of the glenohumeral joint: a cadaveric study. J Orthop Sports Phys Ther 2011;41:311318.

30. Falanga $V$, Bucalo B. Use of a durometer to assess skin hardness. J Am Acad of Dermatol 1993;29:47-51.

31. Piaggesi A, Romanelli M, Schipani E, Campi F, Magliaro A, Baccetti $F$, et al. Hardness of plantar skin in diabetic neuropathic feet. J Diabetes Complications 1999;13:129-134.

32. Merkel PA, Silliman NP, Denton $C P$, Furst $D E$, Khanna $D$, Emery $P$, et al. Validity, reliability, and feasibility of durometer measurements of scleroderma skin disease in a multicenter treatment trial. Arthritis
Rheum 2008:59:699-705.

33. Kissin EY, Schiller AM, Gelbard RB, Anderson JJ, Falanga V, Simms RW, et al. Durometry for the assessment of skin disease in systemic sclerosis. Arthritis Rheum 2006;55:603-609.

34. Belyaev O, Herden H, Meier JJ, Muller CA, Seelig MH, Herzog T, et al. Assessment of pancreatic hardness: surgeon versus durometer. J Surg Res 2010;158:53-60.

35. Hong TH, Choi Jl, Park MY, Rha SE, Lee YJ, You YK, et al. Pancreatic hardness: correlation of surgeon's palpation, durometer measurement and preoperative magnetic resonance imaging features. World J Gastroenterol 2017;23:2044-2051.

36. Yoon YC, Lee JS, Park SU, Kwon JH, Hong TH, Kim DG. Quantitative assessment of liver fibrosis using shore durometer. Ann Surg Treat Res 2017;93:300-304.

37. Mori H, Uemura N, Koga H, Okazaki M. Objective assessment of reconstructed breast hardness using a durometer. Breast Cancer 2018;25:81-85.

38. Kudo S, Nakamura S. Relationship between hardness and deformation of the vastus lateralis muscle during knee flexion using ultrasound imaging. J Bodyw Mov Ther 2017;21:549-553.

39. Sahr M, Sturnick DR, Nwawka OK. Quantitative ultrasound assessment of the achilles tendon under varied loads. J Ultrasound Med 2018;37:2413-2418. 